\title{
Design of Unified Power Quality Conditioner (UPQC) Connected To Three Phase Four Wire System
}

\author{
Paduchuri.Chandra Babu and Subhransu.Sekhar.Dash
}

\begin{abstract}
In this paper presents a Design of a Unified Power Quality conditioner (UPQC) connected to three phase four wire system $(3 \mathrm{P} 4 \mathrm{~W})$. The neutral of series transformer used in the fourth wire for the $3 \mathrm{P} 4 \mathrm{~W}$ system. The neutral current that may flow toward transformer neutral point is compensated by using a four-leg voltage source inverter topology for shunt part The series transformer neutral will be at virtual zero potential during all operating conditions. Here we observe the power quality problems such as unbalanced voltage and current, harmonics by connecting non linear load to 3P4W system with Unified Power Quality conditioner. A new control strategy is proposed to the control algorithm for series APF is based on unit vector template generation to compensate the current unbalance present in the load currents by expanding the concept of single phase $\mathrm{P}-\mathrm{Q}$ theory. The $\mathrm{P}-\mathrm{Q}$ theory applied for balanced three phase system. And also be used for each phase of unbalanced system independently. The MATLAB/Simulink based simulations are provided the functionality of the UPQC.
\end{abstract}

Index Terms - Series active power filter, shunt active power filter three-phase four wire systems (3P4W), P-Q theory, harmonics, power quality, unified power quality conditioner (UPQC).

\section{INTRODUCTION}

The power electronic devices due to their inherent nonlinearity draw harmonic and reactive power from the supply. In three phase systems, they could also cause unbalance and draw excessive neutral currents. The injected harmonics, reactive power burden, unbalance, and excessive neutral currents cause low system efficiency and poor power factor.The use of the sophisticated equipment/loads at transmission and distribution level has increased considerably in recent years due to the development in the semiconductor device technology. The equipment needs clean power in order to function properly. At the same time, the switching operation of these devices generates current harmonics resulting in a polluted distribution system. The power-electronics-based devices have been used to overcome the major power quality problems [1]. A 3P4W distribution system can be realized by providing the neutral conductor along with the 3 power lines from generation station. The unbalanced load currents are very common and an important Problem in 3P4W distribution system [2]. To improve the power quality by connecting the series active power filter (APF) and shunt (APF).They are two types of filters. One is passive filters and another one is active filters.

Manuscript received November 10, 2011; revised February 20, 2012.

Paduchuri. Chandra Babu is pursuing M. Tech in SRM University Chennai. India.

Subhransu Sekhar Dash is presently working as Professor and HOD (EEE) in SRM Engineering College, SRM University, Chennai, India
When compare to passive filters, active filter is better. In passive filters they are using $\mathrm{L}$ and $\mathrm{C}$ components are connected. By connecting passive filters the system is simplicity and cost is very low. And so many dis-advantages is there, that is resonance problems and filter for every frequency and Bucky. By using active filters the power converter circuit using active components like IGBTs,MOSFETs, etc., and energy storage device ( $\mathrm{L}$ or $\mathrm{C}$ ).The advantages are filtering for a range of frequencies and no resonance problems and fast response. But only very few dis advantages is there that is cost is high. By connecting series active filters the voltage harmonic compensation, high impedance path to harmonic currents these are the main functions. All these non-linear loads draw highly distorted currents from the utility system, with their third harmonics component almost as large as the fundamental. The increasing use of non-linear loads, accompanied by an increase in associated problems concerns both electrical utilities and utility customer alike. [3]. In this paper Here we can absorb the power quality problems like voltage and current unbalanced and also reduce the total harmonic distortion (THD) of 3P4W system utilizing $3 \mathrm{P} 3 \mathrm{~W}$ system to connect the UPQC.

\section{THE 3P3W Distribution SYSTEM UtILIZING UPQC}

Generally, a 3P4W distribution system is realized by providing a neutral conductor along with three power conductors from generation station.Fig. 1 shows the $3 \mathrm{P} 3 \mathrm{~W}$ system is connected to UPQC.

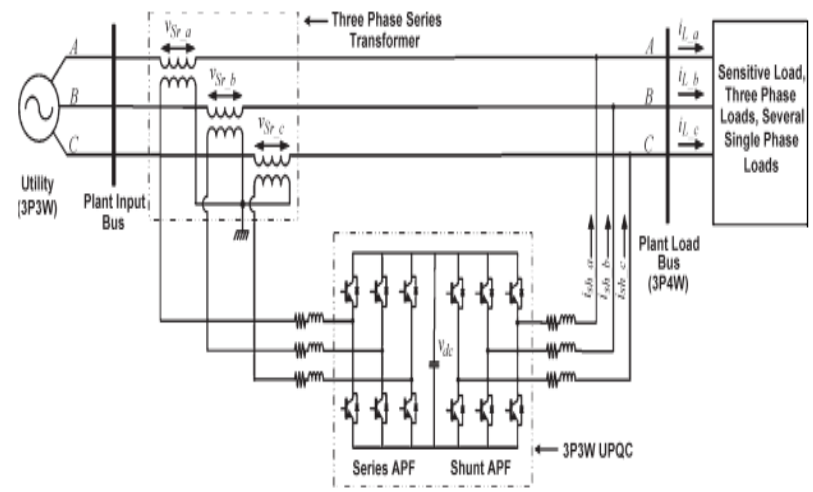

Fig. 1.3P3W system is connected to UPQC.

If we want to upgrade the system now from $3 \mathrm{P} 3 \mathrm{~W}$ to 3P4W due to installation of some single-phase loads and if the distribution transformer is close to the plant under consideration, utility would provide the neutral conductor from this transformer without major cost involvement. In recent cases, this may be a costly solution because the 
distribution transformer may not be situated in close vicinity. Recently, the utility service providers are putting more and more restrictions on current total harmonic distortion (THD) limits, drawn by nonlinear loads, to control the power distribution system harmonics pollution. At the same time, the use of sophisticated equipment or load has increases significantly, and it needs clean power for its proper operation. Fig. 2 shows the novel 3P4W topology that can be realized from a $3 \mathrm{P} 3 \mathrm{~W}$ system. In addition to easy expansion of 3P3W system to 3P4W system.

As shown in Fig.1 the UPQC should necessarily consist of three-phase series transformer in order to connect one of the inverters in the series with the line to function as a controlled voltage source. If we could use the neutral of three-phase series transformer to connect a neutral wire to realize the $3 \mathrm{P} 4 \mathrm{~W}$ system, then $3 \mathrm{P} 4 \mathrm{~W}$ system can easily be achieved from a $3 \mathrm{P} 3 \mathrm{~W}$ system (fig.2). The neutral current, present if any ,would flow through this fourth wire toward transformer neutral point. This neutral current can be compensated by using a split capacitor topology or a four leg voltage source inverter (VSI) topology for a shunt inverter [4], [5].The four-leg VSI topology requires one additional leg as compared to the split capacitor topology.VSI structure is much easier than that of the split capacitor. But here going through the UPQC design by using P-Q theory and it is connected to $3 \mathrm{P} 4 \mathrm{~W}$ system.

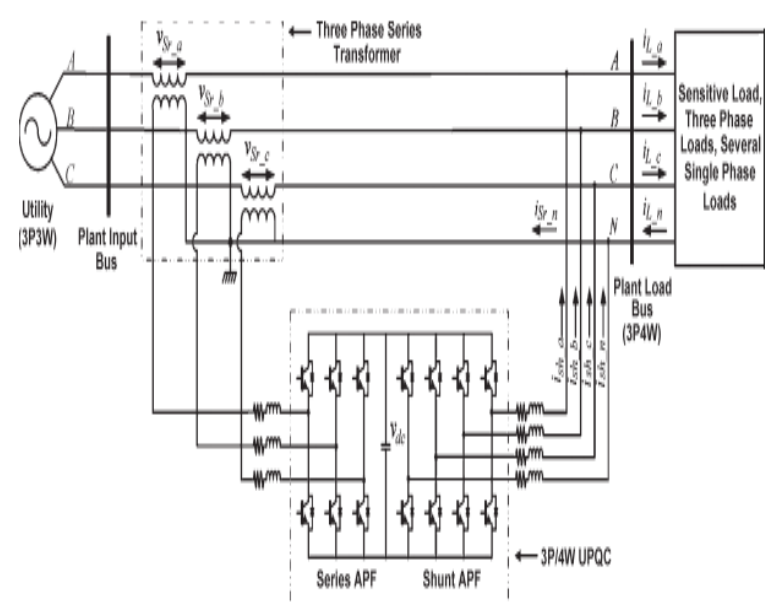

Fig. 2.3. P4W system realized from a 3P3W system utilizing UPQC.

Thus, the structure would help to realize a $3 \mathrm{P} 4 \mathrm{~W}$ system at distribution load end. This would eventually result in easy expansion from $3 \mathrm{P} 3 \mathrm{~W}$ to $3 \mathrm{P} 4 \mathrm{~W}$ systems. A new control strategy to generate balanced reference source currents under load condition is also proposed in this paper and also UPQC design by using P-Q theory is also explained in the next section.

\section{DESIGN OF UPQC CONTROLlER}

\section{A. Description of Implementation of Series APF}

In series APF the Inverter injects a voltage in series with the line which feeds the polluting load through a transformer. The injected voltage will be mostly harmonic with a small amount of sinusoidal component which is in-phase with the current flowing in the line. The small sinusoidal in-phase (with line current ) component in the injected voltage results in the right amount of active power flow into the Inverter to compensate for the losses within the Series APF and to maintain the D.C side capacitor voltage constant. Obviously the D.C voltage control loop will decide the amount of this in-phase component. Series active power filter compensate current system distortion caused by nonlinear load by imposing a high impedance path to the harmonic current [6]. The line diagram of series active power filter is shown in below fig. 3

\section{B. Description of Implementation of Shunt APF}

The active filter concept uses power electronics to produce harmonic current components that cancel the Harmonic current components that cancel the harmonic current components from the non- linear loads. The active filter uses Power electronic switching to generate

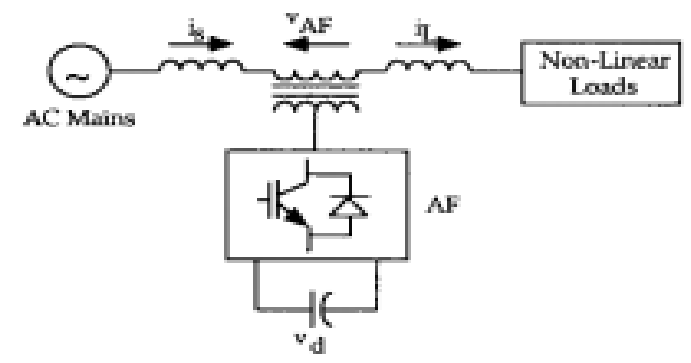

Fig. 3. Line diagram of series active power filter.

Harmonic currents that cancel the harmonic currents from a non-linear load. In this configuration, the filter is connected in parallel with the load being compensated.Therfore the configuration is often referred to as an active parallel or shunt filter [7],[8].

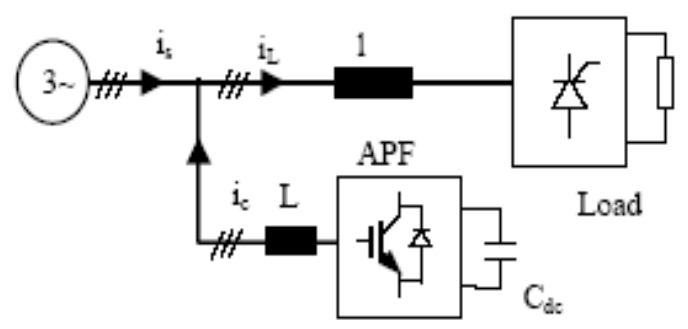

Fig. 4. Shunt active power filter.

Fig.4 illustrates the concept of the harmonic current cancellation so that the current being supplied from the source is sinusoidal. The voltage source inverter used in the active filter makes the harmonic control possible. This inverter uses dc capacitors as the supply and can switch at a high frequency to generate a signal that will cancel the harmonics from the non-linear load.

The control algorithm for series APF is based on unit vector template generation scheme [9]. Where as the control strategy for shunt APF is discussed in this section. Based on the load on the 3P4W system, the current drawn from the utility can be unbalanced. In this paper, the concept of single phase P-Q theory [10]. According to this theory, a single 
phase system can be defined as a pseudo two-phase system by giving $\pi / 2$ lead or $\pi / 2$ lag, that is each phase voltage and current of the original three phase systems. These resultant two phase systems can be represented in $\alpha-\beta$ coordinates, and thus P-Q theory applied for balanced three phase system [11] can also be used for each phase of unbalanced system independently. In order to eliminate these limitations, the reference load voltage signals extracted for series APF are used instead of actual load voltage [12],[13].

For phase a, the load voltage in $\alpha-\beta$ coordinates can be represented by $\pi / 2$ lead as

$$
\begin{array}{r}
{\left[\begin{array}{c}
v_{L a_{-} \alpha} \\
v_{L a_{-} \beta}
\end{array}\right]=\left[\begin{array}{c}
v_{L a}^{*}(\omega t) \\
v_{L a}^{*}(\omega t+\pi / 2)
\end{array}\right]=\left[\begin{array}{c}
V_{L m} \sin (\omega t) \\
V_{L m} \cos (\omega t)
\end{array}\right]} \\
{\left[\begin{array}{c}
i_{L a-\alpha} \\
i_{L a-\beta}
\end{array}\right]=\left[\begin{array}{c}
i_{L a}\left(\omega t+\varphi_{L}\right) \\
i_{L a}\left[\left(\omega t+\varphi_{L}\right)+\pi / 2\right.
\end{array}\right]}
\end{array}
$$

where $v_{L a}^{*}(\omega t)$ represents the reference load voltage and $\mathrm{V}_{\mathrm{Lm}}$ represents the desired load voltage magnitude.

Similarly, for phase $b$, the load voltage in $\alpha-\beta$ coordinates can be represented by $\pi / 2$ lead as

$$
\begin{gathered}
{\left[\begin{array}{l}
v_{L b_{-} \alpha} \\
v_{L b_{-} \beta}
\end{array}\right]=\left[\begin{array}{c}
v_{L b}^{*}(\omega t) \\
v_{L b}^{*}(\omega t+\pi / 2)
\end{array}\right]=\left[\begin{array}{c}
V_{L m} \sin \left(\omega t-120^{\circ}\right) \\
V_{L m} \cos \left(\omega t-120^{\circ}\right)
\end{array}\right]} \\
{\left[\begin{array}{l}
i_{L b-\alpha} \\
i_{L b-\beta}
\end{array}\right]=\left[\begin{array}{c}
i_{L b}\left(\omega t+\varphi_{L}\right) \\
i_{L b}\left[\left(\omega t+\varphi_{L}\right)+\pi / 2\right.
\end{array}\right]}
\end{gathered}
$$

In addition, for phase $\mathrm{c}$, the load voltage in $\alpha-\beta$ coordinates can be represented by $\pi / 2$ lead as

$$
\begin{gathered}
{\left[\begin{array}{l}
v_{L c_{-} \alpha} \\
v_{L c_{-} \beta}
\end{array}\right]=\left[\begin{array}{c}
v_{L c}^{*}(\omega t) \\
v_{L c}^{*}(\omega t+\pi / 2)
\end{array}\right]=\left[\begin{array}{cc}
V_{L m} & \sin \left(\omega t+120^{\circ}\right) \\
V_{L m} & \cos \left(\omega t+120^{\circ}\right)
\end{array}\right]} \\
{\left[\begin{array}{l}
i_{L c-\alpha} \\
i_{L c-\beta}
\end{array}\right]=\left[\begin{array}{c}
i_{L c}\left(\omega t+\varphi_{L}\right) \\
i_{L c}\left[\left(\omega t+\varphi_{L}\right)+\pi / 2\right.
\end{array}\right]}
\end{gathered}
$$

By using the definition of three-phase system [2], the instantaneous power components can be represented as

Instantaneous active power

$$
p_{L, a b c}=v_{L, a b c-\alpha} \cdot i_{L, a b c-\alpha}+v_{L, a b c-\beta} \cdot i_{L, a b c-\beta}
$$

Instantaneous reactive power

$$
q_{L, a b c}=v_{L, a b c-\alpha} \cdot i_{L, a b c-\beta}-v_{L, a b c-\beta} \cdot i_{L, a b c-\alpha}
$$

Considering phase a, the phase- $\alpha$ instantaneous load active and instantaneous load reactive powers can be represented by

$$
\left[\begin{array}{l}
p_{L a} \\
q_{L a}
\end{array}\right]=\left[\begin{array}{cc}
v_{L a-\alpha} & v_{L a-\beta} \\
-v_{L a-\beta} & v_{L a-\alpha}
\end{array}\right] \cdot\left[\begin{array}{c}
i_{L a-\alpha} \\
i_{L a-\beta}
\end{array}\right]
$$

where

$$
\begin{aligned}
& p_{L a}=\overline{p_{L a}}+\widetilde{p_{L a}} \\
& q_{L a}=\overline{q_{L a}}+\widetilde{q_{L a}}
\end{aligned}
$$

In (10) and (11), $\overline{p_{L a}}$ and $\overline{q_{L a}}$ represent the dc components that are responsible for fundamental load active and reactive powers, whereas $\widetilde{p_{L a}}$ and $\widetilde{q_{L a}}$ represent the ac components that are responsible for harmonic powers. The fundamental instantaneous load active and reactive power components can be extracted from $p_{L a}$ and $q_{L a}$, respectively, by using low pass filter (LPF).
Therefore, the instantaneous fundamental load active power for phase a is given by

$$
p_{L a, 1}=\overline{p_{L a}}
$$

And the instantaneous fundamental load reactive power for phase a is given by

$$
q_{L a, 1}=\overline{q_{L a}}
$$

The instantaneous fundamental load active power for phase $b$ is given by

$$
p_{L b, 1}=\overline{p_{L b}}
$$

The instantaneous fundamental load reactive power for phase $\mathrm{a}$ is given by

$$
q_{L b, 1}=\overline{q_{L b}}
$$

The instantaneous fundamental load active power for phase $b$ is given by

$$
p_{L c, 1}=\overline{p_{L c}}
$$

The instantaneous fundamental load reactive power for phase a is given by

$$
q_{L c, 1}=\overline{q_{L c}}
$$

The aforementioned task can be achieved by summing instantaneous fundamental load active power demands of all the three phases and redistributing it again on each utility phase from (12), (14), (16)

$$
\begin{aligned}
& p_{L, \text { total }}=p_{L a, 1}+p_{L b, 1}+p_{L c, 1} \\
& p_{S / p h}^{*}=\frac{p_{L, \text { total }}}{3}
\end{aligned}
$$

Thus, the reference compensating currents are representing a perfectly balanced 3-phase system can be extracted by taking the inverse of (9)

$$
\left[\begin{array}{l}
i_{s a-\alpha}^{*} \\
i_{s a-\beta}^{*}
\end{array}\right]=\left[\begin{array}{cc}
v_{L a-\alpha} & v_{L a-\beta} \\
-v_{L a-\beta} & v_{L a-\alpha}
\end{array}\right]^{-1} \cdot\left[\begin{array}{c}
p_{S / p h}^{*}+p_{d c / p h} \\
0
\end{array}\right]
$$

In (20), $p_{d c / p h}$ is the precise amount of per-phase active power that should be taken from the source in order to maintain the dc-link voltage at a constant level and to overcome the losses associated with UPQC

Therefore, the reference source current for phase $a, b$ and c can be estimated as

$$
\begin{aligned}
& i_{s a}^{*}(t)=\frac{v_{L a-\alpha}(t)}{v_{L a-\alpha}^{2}+v_{L a-\beta}^{2}} \cdot\left[p_{S / p h}^{*}(t)+p_{d c / p h}(t)\right] \\
& i_{s b}^{*}(t)=\frac{v_{L b-\alpha}(t)}{v_{L b-\alpha}^{2}+v_{L b-\beta}^{2}} \cdot\left[p_{l / p h}^{*}(t)+p_{d c / p h}(t)\right] \\
& i_{s c}^{*}(t)=\frac{v_{L c-\alpha}(t)}{v_{L c-\alpha}^{2}+v_{L c-\beta}^{2}} \cdot\left[p_{l / p h}^{*}(t)+p_{d c / p h}(t)\right]
\end{aligned}
$$

The reference neutral current signal can be extracted by simply adding all the sensed load currents, without actual neutral current sensing, as

$$
\begin{gathered}
i_{L-n}(t)=i_{L a}(t)+i_{L b}(t)+i_{L c}(t) \\
i_{S h-n}(t)=-i_{L-n}(t)
\end{gathered}
$$

By using above equations to design the both series and shunt active power filters by connecting the $3 \mathrm{P} 4 \mathrm{~W}$ system as shown in next section. 


\section{Simulation Block Diagram}

The simulation block diagram of 3P4W system realized from a $3 \mathrm{P} 3 \mathrm{~W}$ system utilizing UPQC is shown in below fig.6.Non-linear loads means by connecting power electronics devices to system, by using universal bridge with $\mathrm{R}-\mathrm{L}$ elements is connect to system. The plant load is assumed to be the combination of a balanced three-phase diode bridge rectifier followed by an R-L load, which acts as a harmonic generating load, and three different single phase loads on each phase, with different load active and reactive power demands. By using equations (1), (3) and (5) to design the unit vector template of series APF is shown in fig. 5 and fig. 7 is Series active power filter controller shown in below. And also shunt APF is design by using all above equations is shown in below fig. 8 .

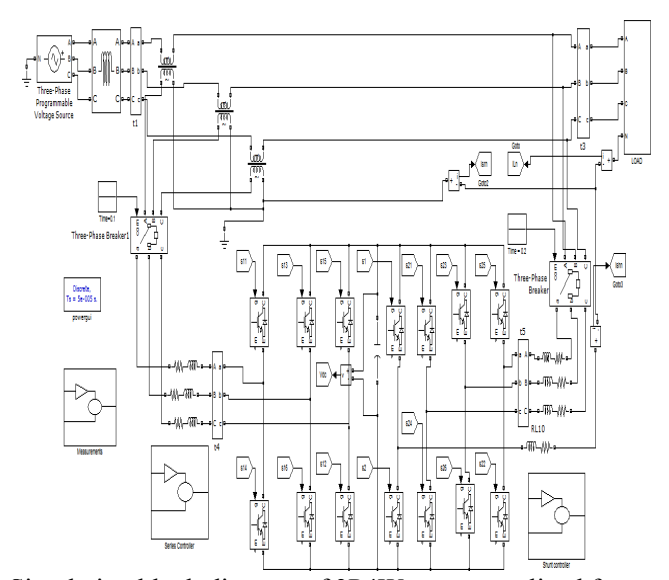

Fig. 6. Simulation block diagram of 3P4W system realized from a 3P3W system utilizing UPQC.

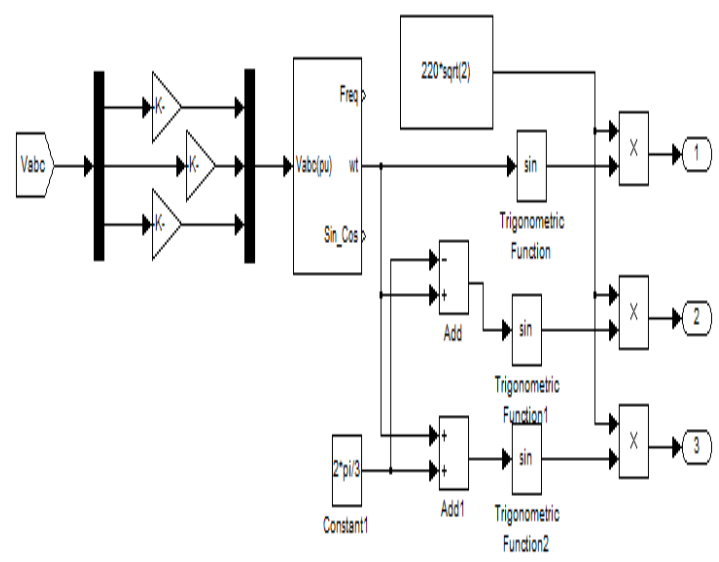

Fig. 5. Simulation block of Unit vector template of series active power filter.

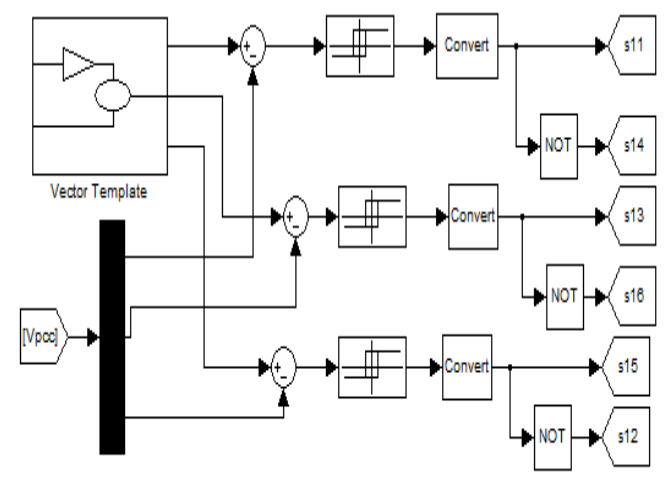

SERIES ACTIVE POWER FILTER ( SAPF)

Fig.7. Simulation block of Series active power filter controller.

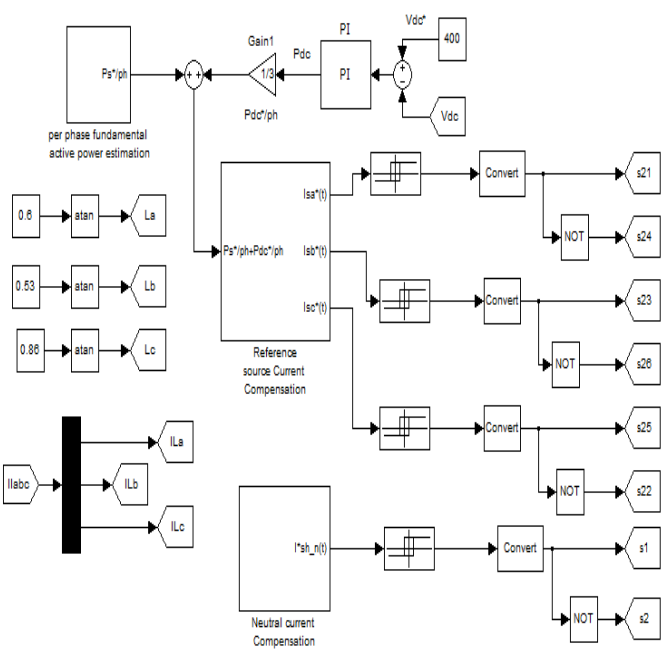

Fig. 8. Simulation block of shunt active power filter.

\section{Simulation Results AND Discussion}

The simulation results for the proposed $3 \mathrm{P} 4 \mathrm{~W}$ system realized from a $3 \mathrm{P} 3 \mathrm{~W}$ system utilizing UPQC are shown in below fig. 9 to 12 .Utility voltage are assumed to be distorted with voltage THD of $14.03 \%$. The distorted voltage profile is shown in fig. 10 in utility voltage. The resulting load current profile shown in figure. 10 has THD of $12.10 \%$. The UPQC should maintain the voltage at load bus at a desired value and free from distortion. The shunt APF is turned on first at time $\mathrm{t}=0.1 \mathrm{sec}$, such that it maintains the dc-link voltage at a set reference value, here $\mathrm{V}=220 \mathrm{~V}$. At time $\mathrm{t}=0.2 \mathrm{sec}$ (is shown in fig.6), the series active power filter injects the required compensating voltages through series transformer, making the load voltage free from distortion $(\mathrm{THD}=1.46 \%)$ and at a desired level as shown in figure. 9 in load voltage. The series active power filter injected voltage profile is shown in fig.9. The compensated source currents shown in fig. 10 are perfectly balanced with the THD of $2.26 \%$.The compensating current injected through the fourth leg of the shunt APF is shown in fig.10.The load neutral current profile is shown in fig.11.In fig.12, the shunt APF effectively compensates the current flowing toward the transformer neutral point. Thus, the series transformer neutral point is maintained at virtual zero potential.

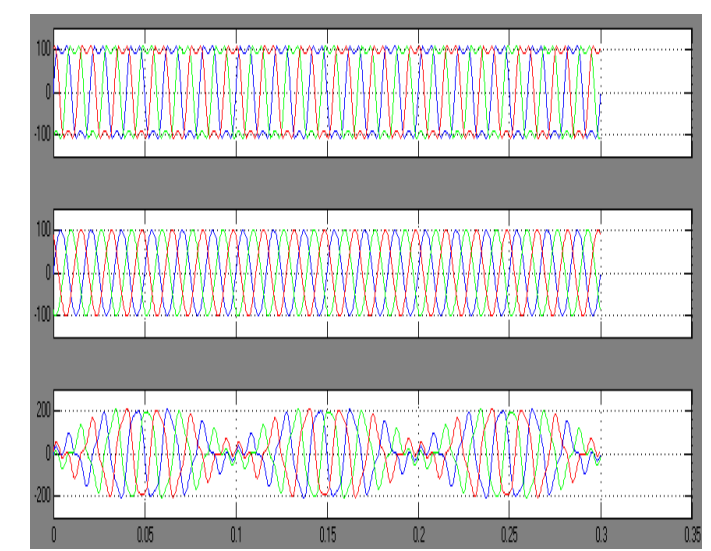

Fig. 9. Utility voltage $\left(v_{S_{-} a b c}\right)$ and load voltage $\left(v_{L_{-} a b c}\right)$ and injected voltage $\left(v_{\text {inj_abc }}\right)$. 


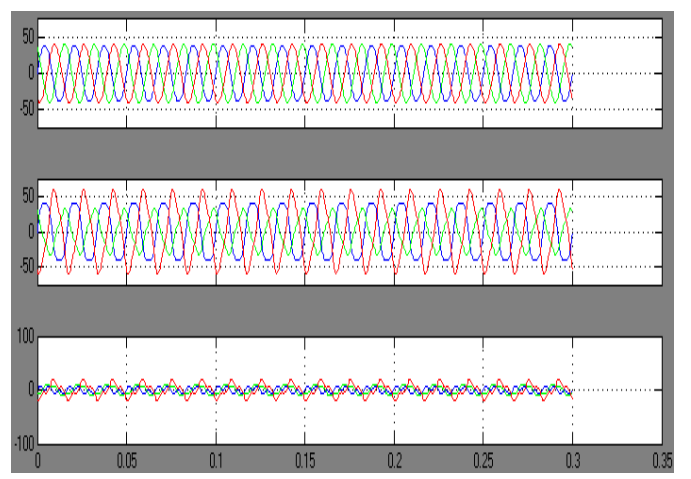

Fig.10. Source current $\left(i_{S_{-} a b c}\right)$ and load current $\left(i_{L-a b c}\right)$ and shunt compensating current $\left(i_{\text {sh_abc }}\right)$.

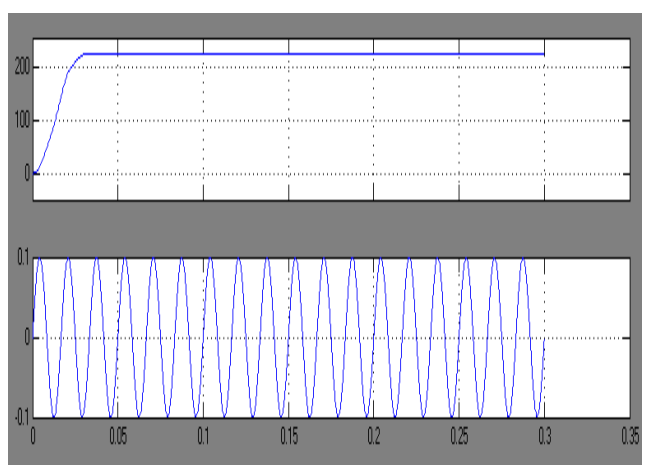

Fig. 11. Current flowing through load neutral wire $\left(i_{L_{-}}\right)$, and Shunt neutral compensating current $\left(i_{S h \_n}\right)$.

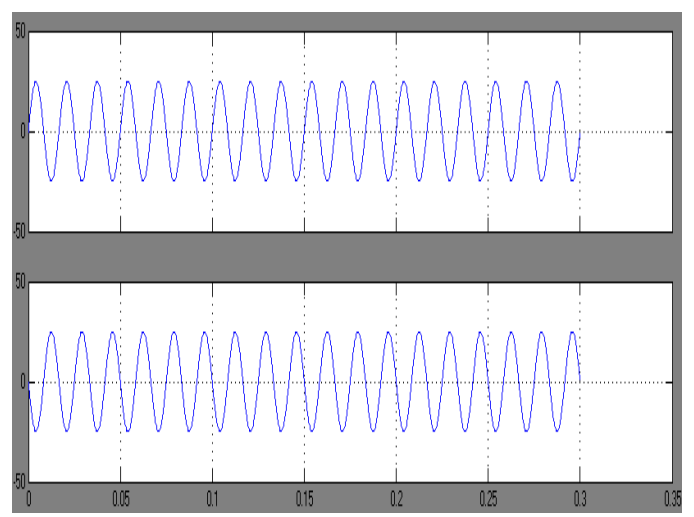

Fig. 12. Dc-link voltage $\left(v_{d c}\right)$, and neutral current flowing towards series transformer $\left(i_{S r_{-} n}\right)$

\section{CONCLUSION}

The design of a unified power quality conditioner (UPQC) connected to $3 \mathrm{P} 4 \mathrm{~W}$ distribution system has been presented in this paper. Where upqc is installed to compensate the different power quality problems, which may play an important role in future upqc- based distribution system. The simulation results shows that the distorted and unbalanced load currents seen from the utility side act as perfectly balanced source currents and are free from distortion. The series transformer neutral will be at virtual zero potential during all operating conditions. Here we can absorb the power quality problems like voltage and current unbalanced and finding the total harmonic distortion (THD) of $3 \mathrm{P} 4 \mathrm{~W}$ system utilizing 3P3W system to connect the UPQC.

\section{REFERENCES}

[1] V. khadkikar and A. Chandra, "A novel structure for three-phase fourwire distribution system utilizing unified power quality conditioner(UPQC)," IEEE Transaction on industry application ,Vol.45,no.5,pp.1897-1902,Sep/oct.2009.

[2] Y. Pal, A. Swarup, and B. Singh, "A comparative analysis of threephase four-wire UPQC topologies, "Power Electronics, Drives and Energy Systems (PEDES) \& 2010 Power India, 2010 Joint International Conference on, On page(s): 1 - 6, Vol. 20-23 Dec. 2010.

[3] M. Aredes, R. M. Fernandes, "A unified power quality conditioner with voltage SAG/SWELL compensation capability," Power Electronics Conference, 2009. COBEP '09. Brazilian, On page(s): 218 - 224, Vol, Sept. 27 2009-Oct. 12009.

[4] M. Aredes, K. Heumann, and E. H. Watanabe, "An universal active power line conditioner," IEEE Trans. power Del., vol.13, no.2, pp.542-551, Apri.1998.

[5] G. Chen, Y. Chen, and K. M. Smedley, "Three-phase four-leg active power quality conditioner without references calculation," in Proc. 19th IEEE APEC, 2004, vol. 1, pp. 829-836.

[6] A. Elnady, M. M. A. Salama, "Unified approach for mitigating voltage sag and voltage flicker using the DSTATCOM,"IEEE Trans. Power Delivery, vol.20, pp.992-1000, April 2005.

[7] J. Puga and J. Ferreira, "Series-shunt power active filter for high penetration of embedded production one dynamic approach," Industrial Electronics (ISIE), 2010 IEEE International Symposium on, On page(s): 2587 - 2592, Vol. 4-7 July 2010.

[8] J. Ferreira, "Series-shunt power active filter for high penetration of embedded production one dynamic approach," Industrial Electronics (ISIE), 2010 IEEE International Symposium on, On page(s): 2587 2592, Vol. 4-7 July 2010.

[9] A. b. Hamadi, K. Al-Haddad, and R. Rahmani, "Series active filter to mitigate power quality for medium size industrial loads," IEEE Int. Conf. onlnd. Electron. 2006, vol.2, pp.15-101515.

[10] M. T. Haque, "Single-phase PQ theory," in Proc. 33rd IEEE PESC, 2002, vol. 4, pp. 1815-1820.

[11] F. A. L. Jowder, "Modeling and Simulation of Dynamic Voltage Restorer (DVR) Based on Hysteresis Voltage Control," in Proc. IEEE Conf. on Industrial Electronics Society, 2007, pp.1726-1731.2007.

[12] V. K hadkikar, A. Chandra, A. O. Barry, and T. D. Nguyen, "Application of UPQC to protect a sensitive load on a polluted distribution network," in Proc. IEEE PES General Meeting. Montreal, QC, Canada, 2006, 6 pp.

[13] J. M. Correa ,S. Chakraborty, M. G. Simoes, and F. A. Farret, "A single phase high frequency $\mathrm{AC}$ micro grid with an unified power quality conditioner," in Conf.Rec. $38^{\text {th }}$ IEEE IAS Annu.Meeting,2003,vol.2,pp.956-962.2003.

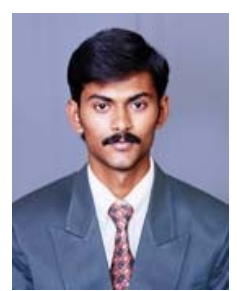

Paduchuri. Chandra Babu. This author becomes a Member (M) of IACSIT, Graduate Student Member (GS) of IEEE. Born in Thokalapalli, Porumamilla, Kadapa on June 18, 1987.He received graduated in 2010 from SISTAM, Srikakulam, JNTU Kakinada, AP, and India. Currently pursuing M.Tech in SRM UNIVERSITY Chennai (with specialization in Power Electronics and drives).Area of Interests includes Power System operation, Control \& Power Electronic Converters, Drives and FACTS, Power quality improvement. He has published more number of international papers on FACTS and Power Quality improvement.

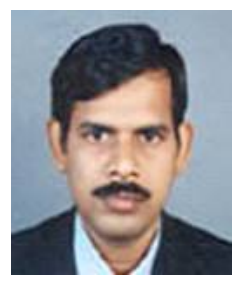

Subhransu Sekhar Dash .This author becomes a Member (M) of IEEE. He received A.M.I.E graduation from I.E (India),Calcutta,India.The M.E Degree from U.C.E, Burla, Orissa, India,(with specialization in power systems) and the Ph.D degree in Electrical Engineering from Anna University College of Engineering,Guindy,Chennai-25 in 1994,1996 and 2006 respectively. He has published more number of Papers in National and International reputed Journals. He is presently working as Professor and HOD (EEE) in SRM Engineering College, SRM University, Chennai, India and his areas of interests include FACTS, Power System Operation, Control \&Stability, Power Electronics Drives and Intelligent Controlling Techniques. 